\title{
3D Mapping of the Submerged Crowie Barge Using Electrical Resistivity Tomography
}

\author{
Kleanthis Simyrdanis $\mathbb{D}^{1,2}$ Ian Moffat, ${ }^{1}$ Nikos Papadopoulos, ${ }^{2}$ \\ Jarrad Kowlessar, ${ }^{1}$ and Marian Bailey ${ }^{1}$ \\ ${ }^{1}$ Archaeology, College of Humanities, Arts and Social Sciences, Flinders University, Adelaide, SA, Australia \\ ${ }^{2}$ Laboratory of Geophysical-Satellite Remote Sensing, Institute for Mediterranean Studies, Rethymno, Greece \\ Correspondence should be addressed to Kleanthis Simyrdanis; ksimirda@ims.forth.gr
}

Received 29 December 2017; Accepted 19 March 2018; Published 8 May 2018

Academic Editor: Yun-tai Chen

Copyright (C) 2018 Kleanthis Simyrdanis et al. This is an open access article distributed under the Creative Commons Attribution License, which permits unrestricted use, distribution, and reproduction in any medium, provided the original work is properly cited.

\begin{abstract}
This study explores the applicability and effectiveness of electrical resistivity tomography (ERT) as a tool for the high-resolution mapping of submerged and buried shipwrecks in 3D. This approach was trialled through modelling and field studies of Crowie, a paddle steamer barge which sunk at anchor in the Murray River at Morgan, South Australia, in the late 1950s. The mainly metallic structure of the ship is easily recognisable in the ERT data and was mapped in 3D both subaqueously and beneath the sedimentwater interface. The innovative and successful use of ERT in this case study demonstrates that 3D ERT can be used for the detailed mapping of submerged cultural material. It will be particularly useful where other geophysical and diver based mapping techniques may be inappropriate due to shallow water depths, poor visibility, or other constraints.
\end{abstract}

\section{Introduction}

During the last few years there has been an increasing trend of employing the electrical resistivity method in subaqueous areas for geological and environmental studies $[1,2]$ and underwater geological mapping [3]. A number of methodological studies on the use of ERT in the aquatic environment have been undertaken, including investigating the most appropriate electrode position and array type. Orlando [4] used numerical simulation modelling to investigate the resolution of underwater resistivity surveys, employing both floating and submerged electrodes. Her results showed that floating cables give low resolution data when the contrast between the resistivity of water and sediment layer is too small. Submarine electrical resistivity data can be collected utilising different electrode arrays such as Dipole-Dipole or Pole-Dipole which are the most widely used ones due to their simple geometry and high data density. In addition, Orlando discusses the Schlumberger array which gives comparable results [4] and Rucker et al. recommend a Pole-Pole array for the collection of marine resistivity data [3]. Baumgartner and Christensen [5] describe a particular array where probes are vertically aligned to increase the investigation depth for mapping resistivity anomalies located at greater water depth. Chiang et al. [6, 7] studied the efficiency of a marine towed electrical resistivity method and its sensitivity using $2 \mathrm{D}$ numerical simulation modelling as a well-suited method for methane hydrate exploration at a shallow depth beneath the seafloor.

However the use of electrical resistivity method in submarine archaeology prospection studies is not common. Ranieri et al. ([8]:11) studied the development and application of an integrated methodology for the 3D rendering of geoelectrical data of buried and submerged archaeological features, in complex environments such as coastal areas. A comprehensive feasibility study was also undertaken, investigating the efficiency of ERT in reconstructing submerged archaeological relics (e.g., building foundations) in shallow seawater environment through numerical modelling and field experimentation [9]. The study showed that floating and 


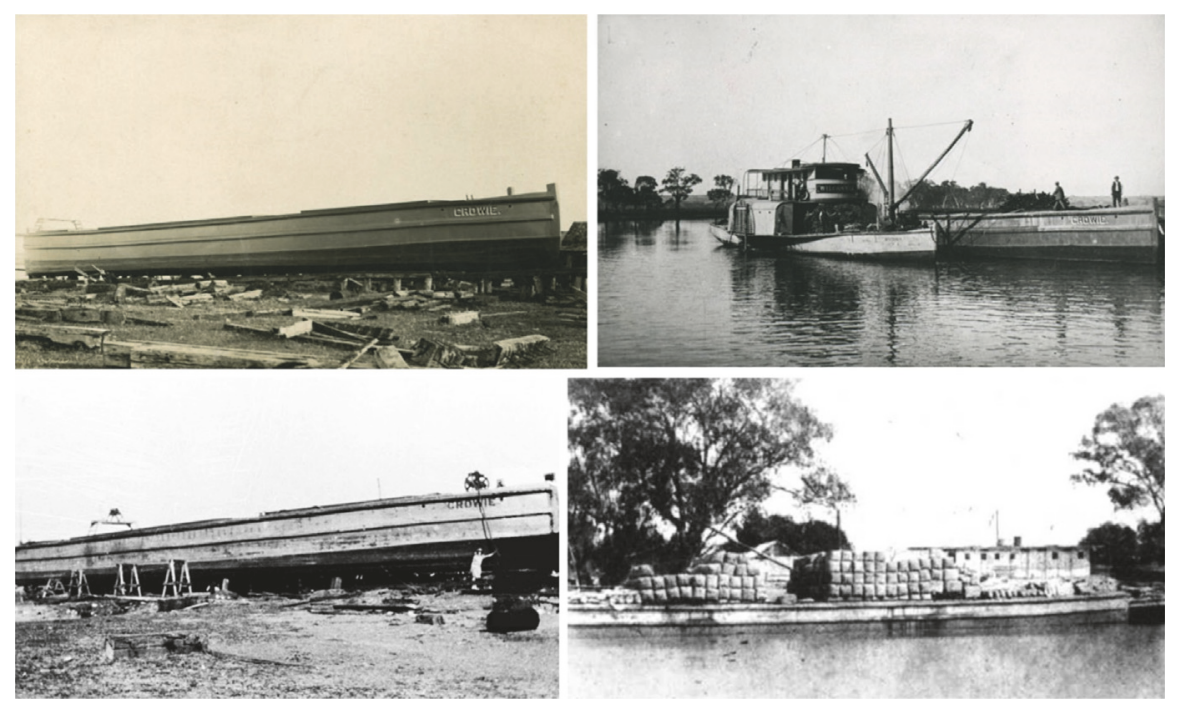

Figure 1: Photos of the Crowie barge (courtesy photograph of the State Library of South Australia, previously published in [13]: 138).

submerged survey modes can be used with equal success in cases of relatively shallow marine environments when the water depth does not exceed $1 \mathrm{~m}$. In deeper marine environments, the submerged mode survey is recommended for outlining isolated targets. Valid a priori information, in terms of the seawater resistivity and thickness, is important and can greatly improve the inversion results for the data captured with the submerged ERT mode. On the other hand, erroneous information can cause severe distortions in the inversion ERT models and misleading interpretations. Passaro et al. used multibeam bathymetry, seismic, geoelectric, and magnetic methods to investigate archaeological targets protruding from very shallow water [10]. Passaro ([11]: 3) also used electrical resistivity survey to detect a shipwreck in Salerno, southern Italy.

Despite this interest, ERT so far appears not to have been used to map a shipwreck in detail. ERT is particularly useful in cases when the water is too turbid for visual surveys and the water depth is too shallow for acoustic techniques. Furthermore, since many ships are metal-based structured, they become easily detectable with ERT when the target is located in an electrically high resistivity environment such as sand.

\section{Crowie Shipwreck}

The present study undertook a high-resolution survey of the barge Crowie, which is submerged in the Murray River (South Australia). Crowie was a commercial cargo barge, built in 1911 by Captain J. G. Arnold. It is claimed to be one of the largest barges ever built for the Murray River ([12]: 63; in [13]:137), and its enormous size is recorded in historical accounts as causing several accidents when traveling up the river. Crowie was eventually superseded by other transport methods and was abandoned near the Morgan wharf where it sank at its mooring, sometime between 1946 and 1950 ([13]: 137) (Figure 1).

The dimensions of Crowie and its structural composition are well recorded in historical records as well as from previous multibeam and side-scan sonar surveys (summarised by [13]) (Figure 2). The barge is $45 \mathrm{~m}$ long, with a $9 \mathrm{~m}$ beam and depth from the base of the hold to the deck of $2.5 \mathrm{~m}$ ([13]: 140). It was built using a bottom-based construction technique. This led to a flat bottom and straight sides amenable to carry the maximum possible amount of cargo ([13]: 141). The vessel had one deck, a carvel built sharp stern, straight stem, and a composite construction consisting of iron frames and topsides overlain by timber. It had nine internal bulkheads ([13]: 139).

The vessel sits upright in a known location immediately upstream of the Morgan wharf and downstream of the wreck of the PS Corowa. The vessel slightly protrudes from the water during low water periods and extends to a depth of several meters. The extremely turbid water of the Murray makes a visual assessment of the wreck impossible; however geophysical data and inspection of the wreck by touch suggest it is largely intact below the deck-level for its entire length ([13]: 139). The frames of the vessel are intact and easily identifiable. Any iron topsides that were on the vessel at the time of wrecking have corroded away; however metal below a depth of $15 \mathrm{~cm}$ below the waterline is believed to be largely intact ([13]: 139).

The large amount of metal used in the construction of the Crowie vessel is likely to give it a highly conductive electrical signature, which should contrast significantly the fresh water and sand which host the wreck. For that reason, electrical resistivity tomography can be considered an appropriate method to apply to this survey, in order not only to detect the specific "target" and define its dimensions (as the previous methods successfully accomplished) but also to estimate its 


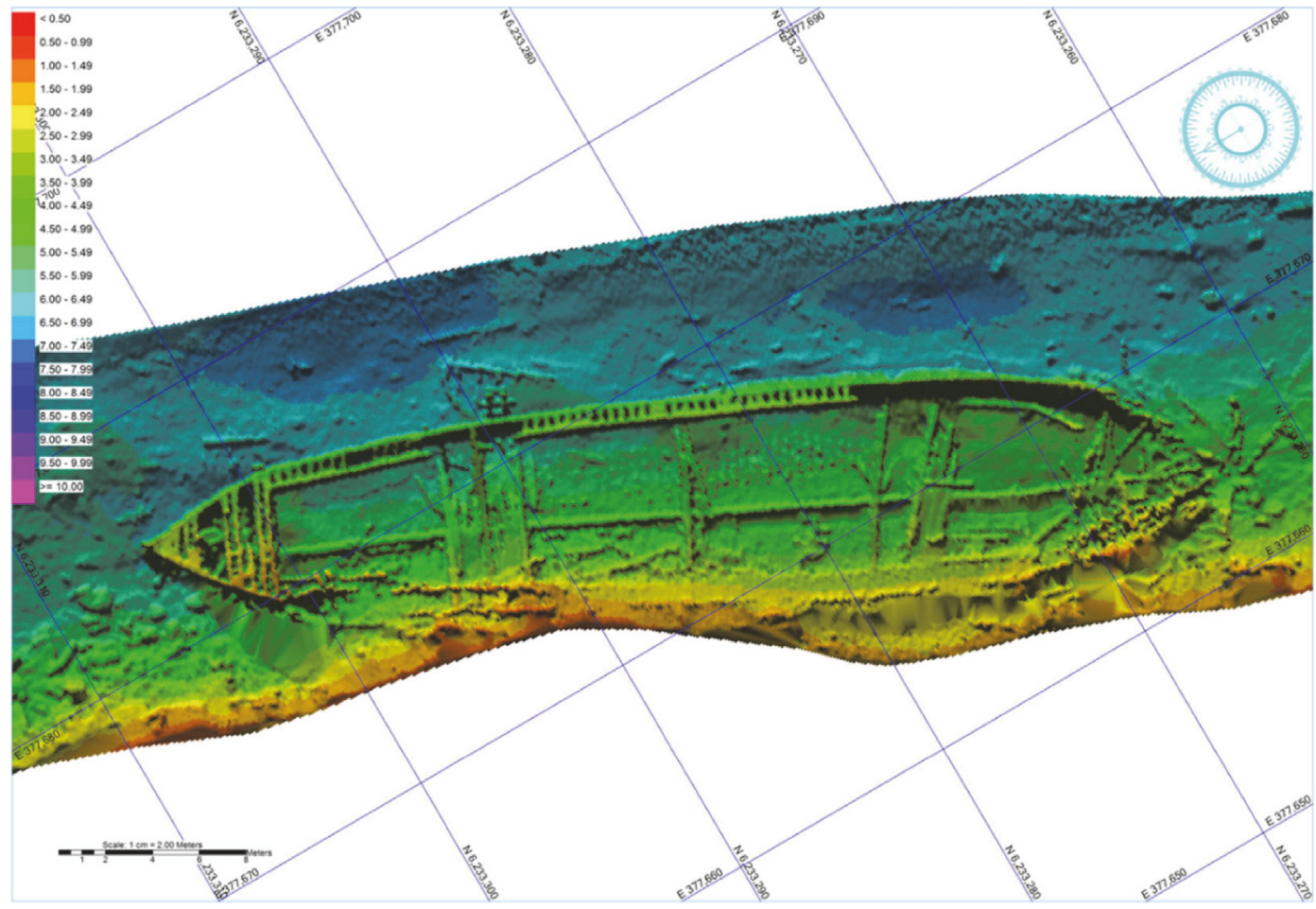

Figure 2: Multibeam image of the Crowie barge (courtesy image of Gareth Carpenter, previously published in [13]: 141).

burial depth and confirm the nature of the material that the barge is composed of.

\section{Methodology}

Initially the viability of the proposed field survey was validated using data produced from a three-dimensional numerical simulation model. The ERT numerical experiments were performed using $3 \mathrm{D}$ forward and inversion algorithms within the "Res3DMod" and "Res3DInvx64" software [14]. A finiteelement modelling subroutine was used to calculate the apparent resistivity values, and a nonlinear smoothnessconstrained least-squares optimisation technique was used to calculate the resistivity of the model blocks [15]. The model was constructed with parameters approximating those expected for the field site.

The indicative model used for the numerical simulations included a water layer $D=6 \mathrm{~m}$ thick (under the air halfspace) and three homogenous medium layers $D_{1}=3.5 \mathrm{~m}$, $D_{2}=1 \mathrm{~m}$, and $D_{3}=1.5 \mathrm{~m}$ as shown in Figure 3 . The resistivity value of the water layer was set to $\rho_{\text {water }}=$ $28 \mathrm{ohm} \cdot \mathrm{m}$ and for the homogeneous layers was set to $\rho_{1}=$ $300 \mathrm{ohm} \cdot \mathrm{m}, \rho_{2}=1500 \mathrm{ohm} \cdot \mathrm{m}$, and $\rho_{3}=150 \mathrm{ohm} \cdot \mathrm{m}$, respectively. The above resistivity values were estimated based on the local geological map and descriptions of the lithology of units within the Murray Basin [16-18]. A conductive target, which simulated a metallic ship structure (shape was defined according to the multibeam image results in [13]: 141), was embedded in the first layer with dimensions $5.5 \mathrm{~m}$ width and $12.5 \mathrm{~m}$ length. Internal divisions were also included denoting the different compartments of the upper part of the barge. The resistivity value for the target's structure was set to $\rho_{\text {target }}=$ $0.05 \mathrm{ohm} \cdot \mathrm{m}$.

The grid $(10 \times 15 \mathrm{~m})$ for the numerical simulation was constructed using 672 electrodes (21 lines of 32 electrodes) with spacing $a=0.5 \mathrm{~m}$ in both directions $(X, Y)$. The electrodes were submerged in the water bottom $6 \mathrm{~m}$ below the water surface. A Pole-Dipole (including the combination of forward and reverse measurements where the electrode B was placed at a theoretically infinite distance) and maximum separation distance $N=11 a$ (" $a$ " unit electrode spacing) was selected and 29618 apparent resistivity measurements were simulated. Data were corrupted with $10 \%$ Gaussian noise so that the simulation data were approaching the real noise levels that would be expected in the field. A priori information for constraining the inversion procedure was included, taking into consideration the water depth and the resistivity of the water. The inversion algorithm was terminated after seven iterations unless some other criteria were met (e.g., slow convergence rate of less than $3 \%$, RMS error smaller than the noise level).

The outer structure of the ship was reproduced quite accurately within the dimensions of the constitutive model's dimensions (Figure 4). The reconstructed resistivity depth sections clearly depict the outer structure of the metal target, with resistivity values close to $0.05-0.2 \mathrm{ohm} \cdot \mathrm{m}$ from $0 \mathrm{~m}$ to the depth of $1 \mathrm{~m}$ below water bottom (depth layers $D 1-D 4$ ). The inner divisions of the barge are not well resolved except for the main axis of the barge which is more obvious at depth slices D3 to D5. Although the target extends no more than 

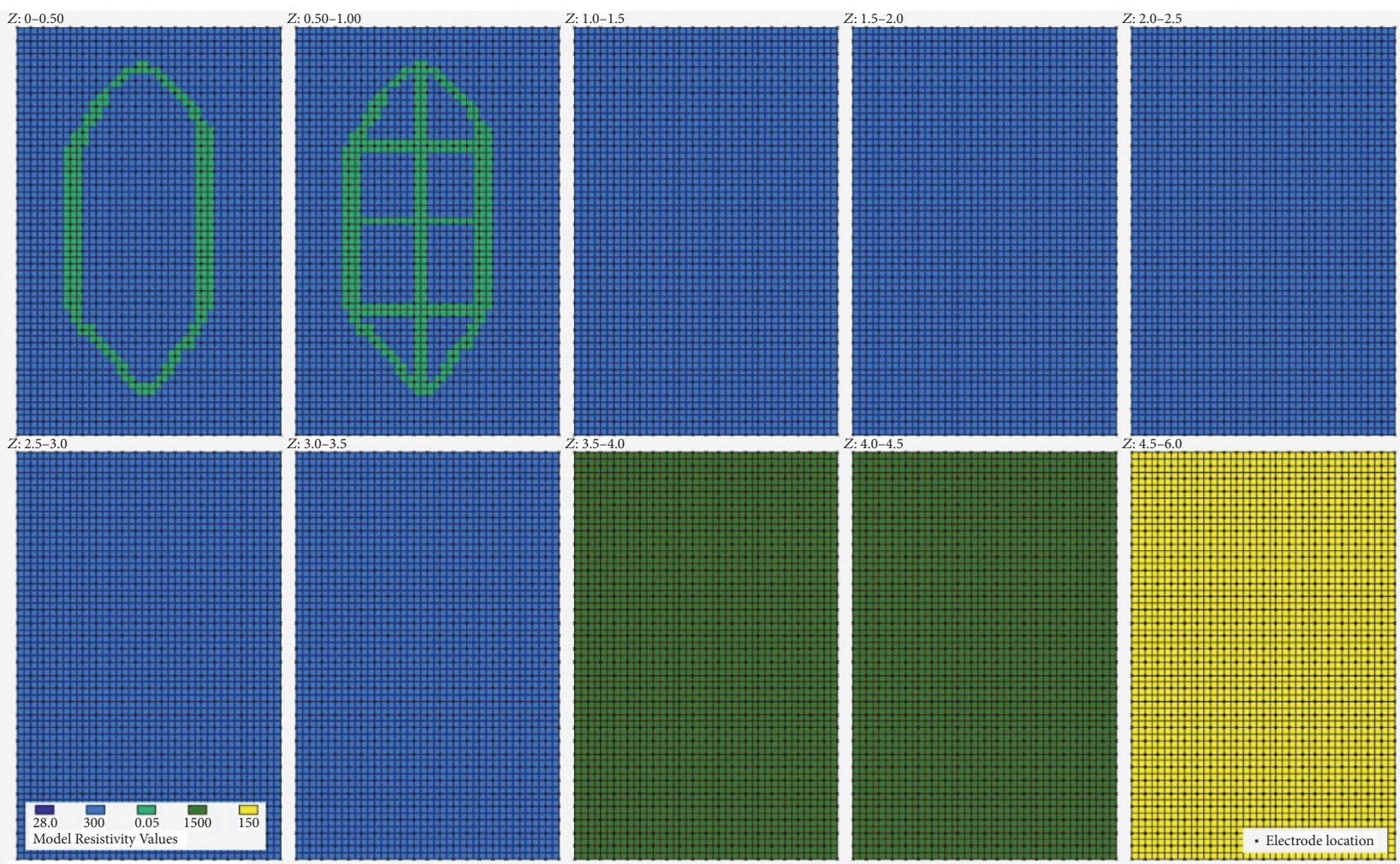

FIgURE 3: Constitutive parameters of 3D model.

$1 \mathrm{~m}$ in depth (D4) below the water bottom (according to the model), the inversion result depicts the target (with distorted shape) continuing to $5 \mathrm{~m}$ below the water bottom ( $D 5$ to $D 11$ ). The upper background highly resistive layer $(0 \mathrm{~m}$ to $3.5 \mathrm{~m}$, $D 1-D 10)$ is represented with a range of gradually increased resistivity values from 150 to $300 \mathrm{ohm} \cdot \mathrm{m}$. The deeper layers (D11-D12) are represented with values close to $1600 \mathrm{ohm} \cdot \mathrm{m}$. The numerical limitations of the modelling and inversion procedures cannot efficiently cope with the magnitude of the resistivity contrast between the conductive target and the resistive background. Hence, the RMS error was high with values reaching almost $30 \%$ after 6 iterations.

\section{Field Case Study}

Following the theoretical modelling of this feature, field survey was undertaken on Crowie. The barge Crowie was submerged near the bank of the Murray River in Morgan (South Australia) (Figure 5). The exact position of the target is described in Roberts et al. [13].

The study area is located in the Murray Basin, epicratonic sedimentary basin of Paleocene to Quaternary age [18]. This basin contains a sedimentary sequence up to $600 \mathrm{~m}$ thick including freshwater, marine, coastal, and continental sediments $[17,18]$. At the survey location the stratigraphy includes the Oligocene aged Ettrick Formation, the EarlyMiddle Miocene aged Mannum Limestone, and a number of
Quaternary aged aeolian units ([16]; see Figure 6). The Quaternary aeolian sediments are estimated to have a resistivity value of $\rho_{\text {sand }}=300 \mathrm{ohm} \cdot \mathrm{m}$, the Mannum Limestone has a value of $\rho_{\text {limestone }}=1500 \mathrm{ohm} \cdot \mathrm{m}$, and the Marly Ettrick Formation has a value of $\rho_{\text {marl }}=150 \mathrm{ohm} \cdot \mathrm{m}$.

4.1. Data Acquisition (Grid, Equipment). The survey grid was set as a 60 by $15.5 \mathrm{~m}$ rectangle approximately parallel to the riverbank as shown in Figure 7 . The four corners of the grid were established using heavy rocks as anchors, making sure that they would be unmovable and stable throughout the fieldwork, with taut ropes running vertically from the anchor to a float on the surface. At the extremities of the grid, measuring tapes were floated as guidelines between these anchors for determining the position of each survey line.

The data were acquired using 58 parallel lines (length of each line $15.5 \mathrm{~m}$ ) oriented perpendicular to the bank and equally spaced ( $L=1 \mathrm{~m}$ apart). The sensors (32 electrodes), equally spaced ( $a=0.5 \mathrm{~m}$ apart) on each survey line, were submerged on the water bottom on top of the sunken ship perpendicular to its length.

A ZZ FlashRES-Universal resistivity meter was used for injecting and measuring the potential throughout the survey. The water conductivity value and temperature were measured daily with a YSI Pro-1030 hand-held conductivity meter. The average value of conductivity $(\rho=28 \mathrm{ohm} \cdot \mathrm{m})$ was used as a priori information for the inversion procedure. A PoleDipole array was used for data collection with a total of \#1498 

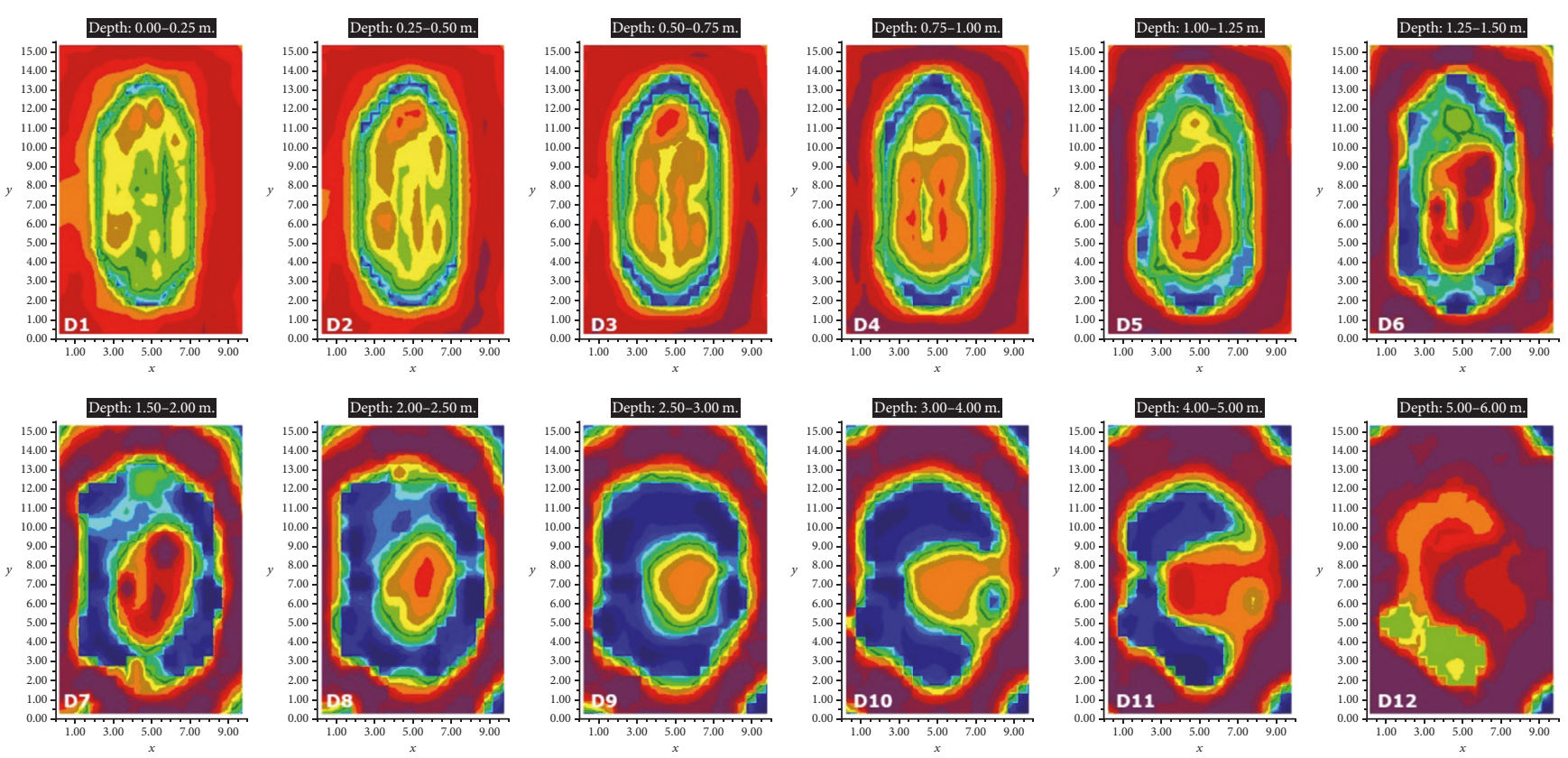

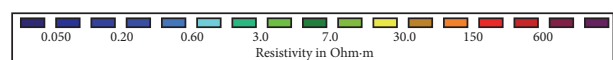

FIGURE 4: 3D inversion depth slices. Resistivity values mapped on a logarithmic scale. Both axes are given in meters.

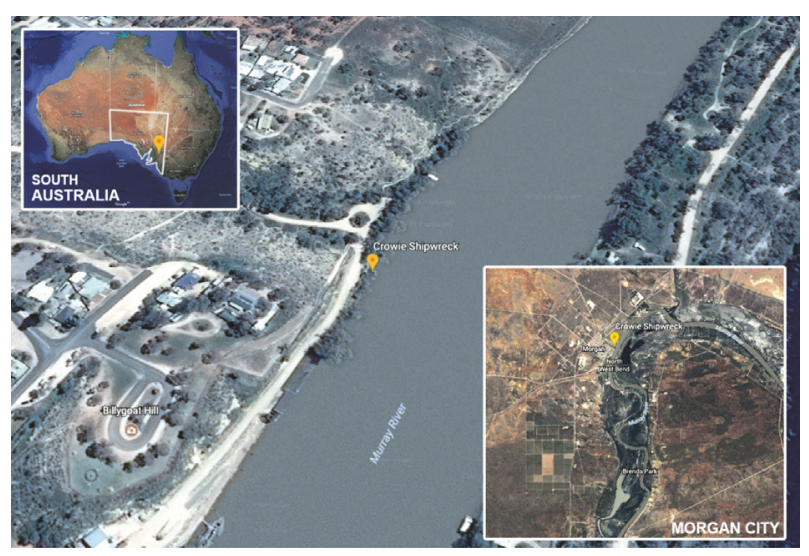

FIgURE 5: Map of the survey area in Morgan (South Australia).

measurements (consisting of 749 forward and 749 reverse measurements). The distance " $a$ " between the dipole "MN" varied between 0.5 and $4 \mathrm{~m}$. The distance factor " $n$ " between electrode "A" and dipole "MN" varied from 1 to $8 a$.

4.2. Data Acquisition (Bathymetry). A total station survey was conducted over the wreck site using a Leica TS16 to measure the river depth in the location of the ERT survey. The position of the total station was georectified based on two static GPS points collected with a CHC 90+ GPS postprocessed using the Auspos service. The position of all bathymetry points were recorded using a prism mounted on a 7.37-meter long pole which was placed on the river bottom by an operator in a small boat. The bathymetric survey recorded 116 points on the bottom of the river around the study area. The points were distributed around the survey area spaced out to ensure reasonable site coverage. The water level was recorded using a prism held at the water surface at 8 different locations. To calculate the bathymetry of the study area, a surface was interpolated using the Inverse Distance Weighting (IDW) surface interpolation function in ESRI ArcGIS software package. The IDW interpolation is a local neighborhood interpolation method, which estimates unknown values based on the distance and values of nearby known points. This interpolation method was chosen due to the limited number of points selected and the heterogeneity of the measured values (which is thought to be based on debris on the river bottom). Unlike kriging or other geostatistical surface interpolations, IDW should be less affected by the potential outliers in the data set [19]. The surface was calculated using a variable search radius with 12 points and no maximum distance selected.

The surface produced can be seen in Figure 8(a). No bounding box was used for the surface interpolation, so the values produced are only accurate within the $60 \times 15.5 \mathrm{~m}$ survey grid. The resulting surface provided elevations based on the Australian Height Datum for a continuous surface covering the study area. To calculate the water depth, the raster calculator tool was used to create a new raster surface, by subtracting the elevation of the river bottom from the average water surface elevation. This produced a continuous surface describing the depth of the water for the site.

The surface describing water depth for the site can be seen in Figure 8(b). Individual ERT lines were surveyed with a total 
RENMARK

GEOLOGICAL SURVEY OF SOUTH AUSTRALIA

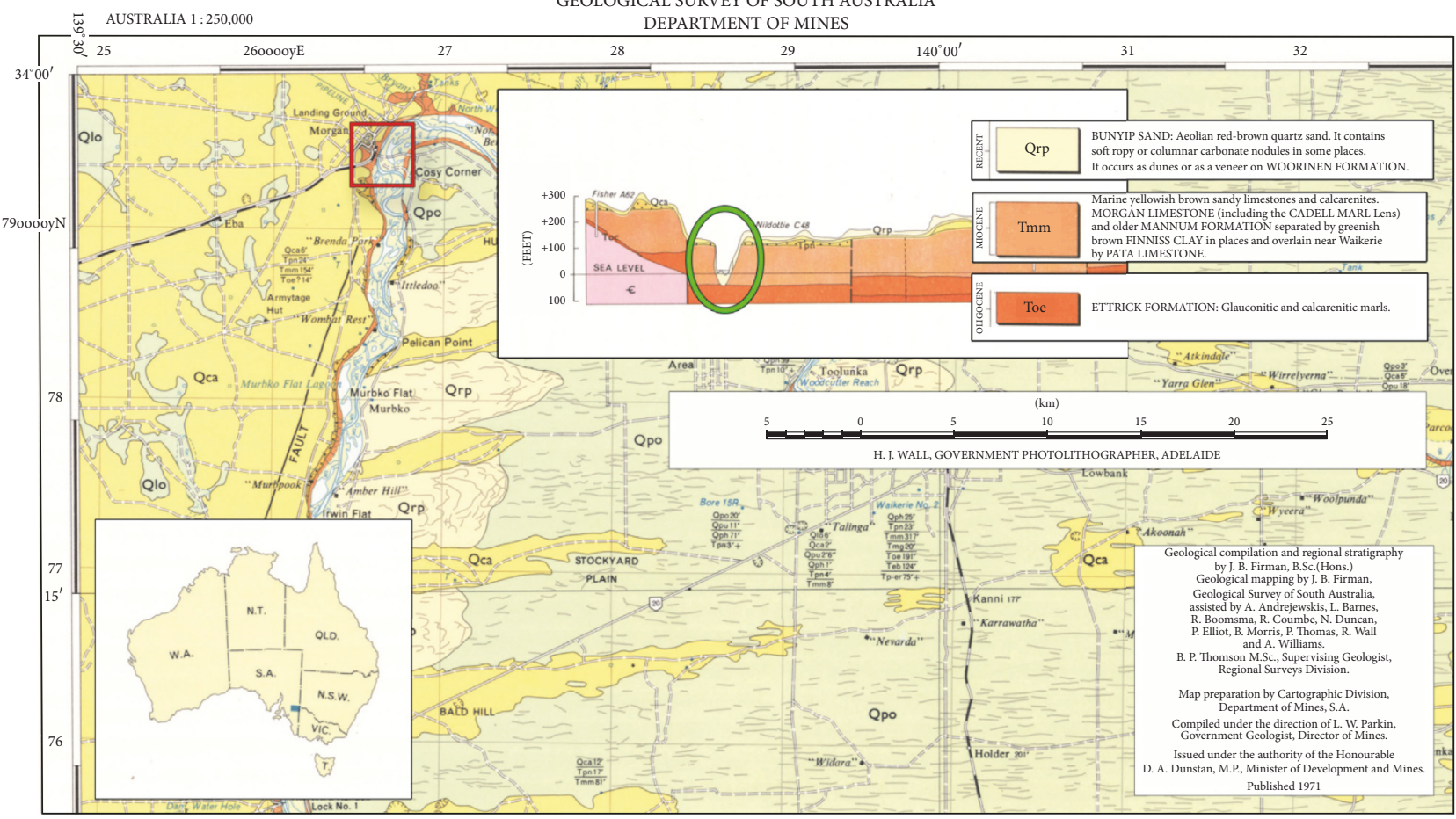

Figure 6: Geological map of the broader survey area (modified from [16]).

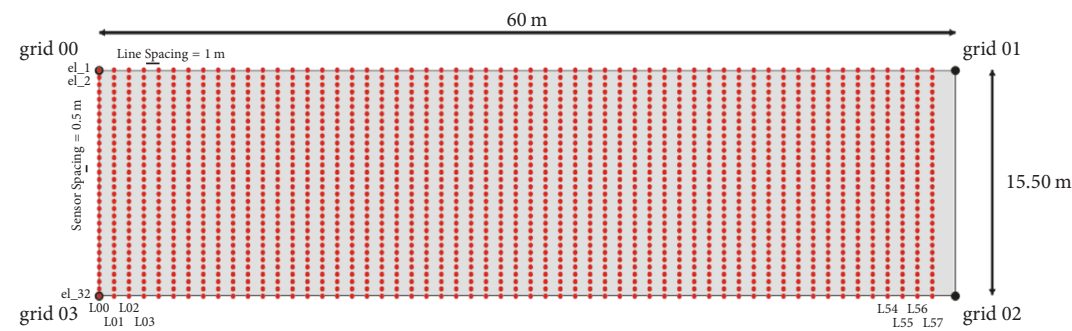

BANK

(a)

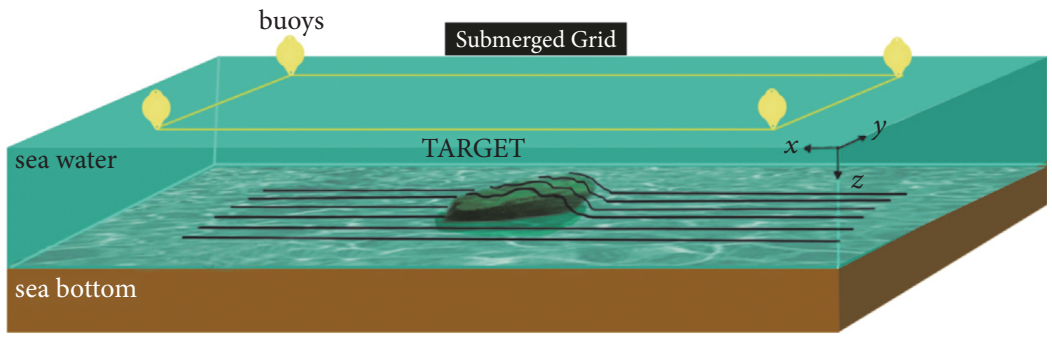

(b)

FIGURE 7: Selected survey grid. Red dots indicating electrode position (a). Cables submerged at the river (b). 


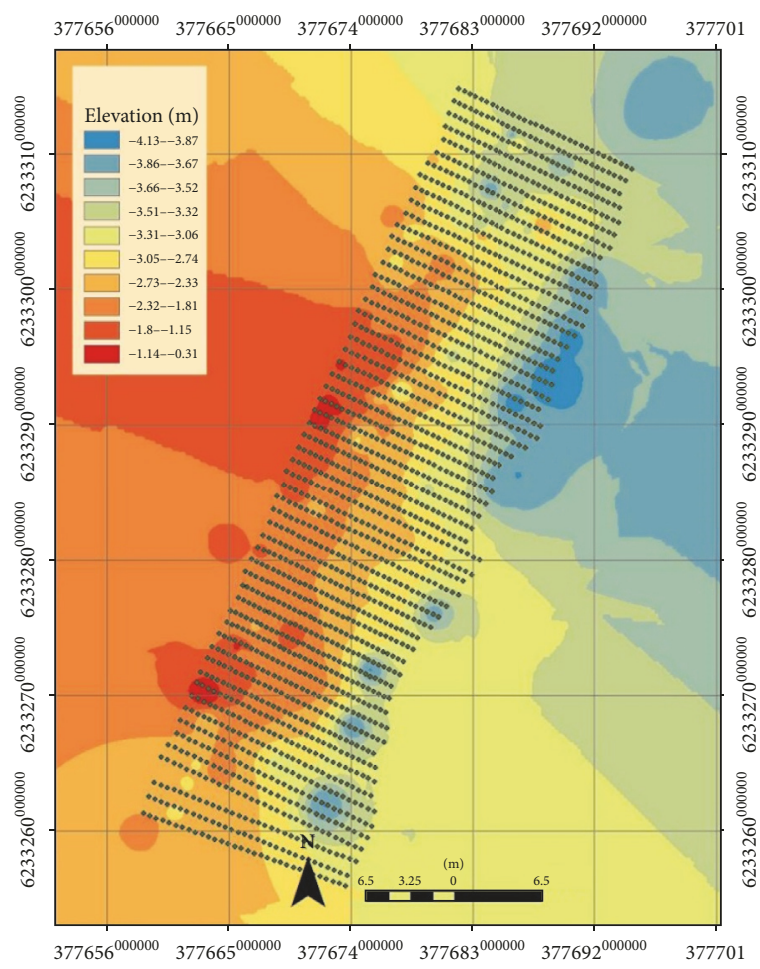

(a)

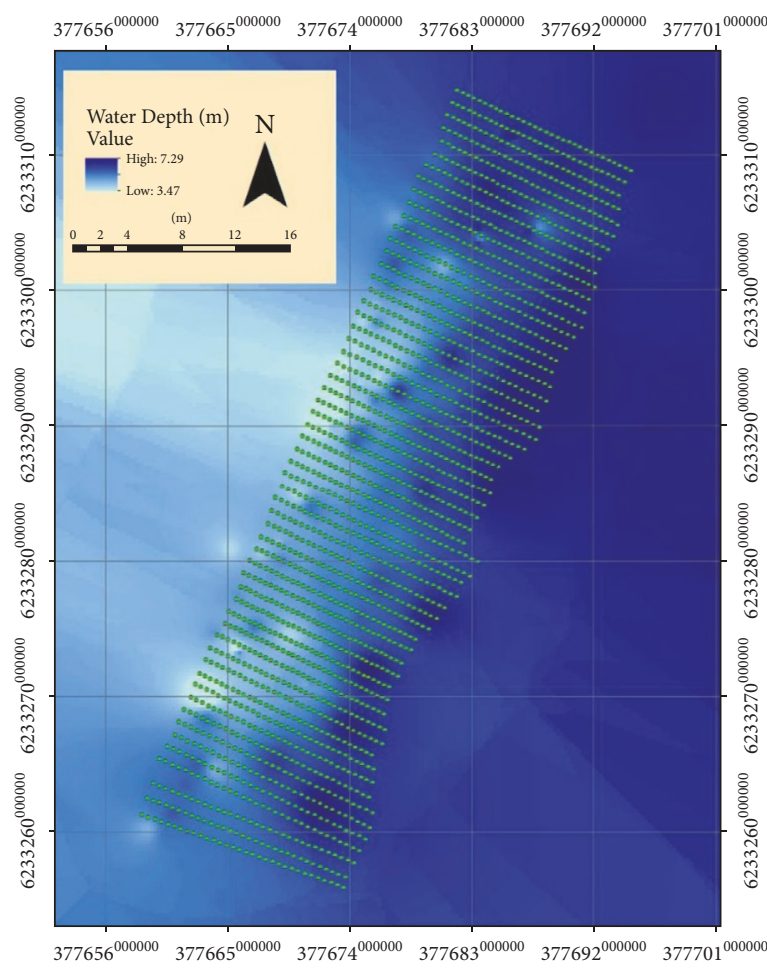

(b)

FIGURE 8: Elevation (a) and bathymetry (b) model. The dots represent the electrode positions.

station marking the start and end position of each line. The individual sensor locations were estimated by evenly spacing a number of points along the length of the measured line, using the "Points Along Line" tool in ESRI ArcGIS software package. An attribute was calculated for all sensors based on the water depth for use in later ERT processing. The elevation (above sea level) for the survey area was between $-0.31 \mathrm{~m}$ and $-4.13 \mathrm{~m}$ which corresponds to water depths between $3.47 \mathrm{~m}$ and $7.29 \mathrm{~m}$.

4.3. Data Processing. In total, 112,984 raw data measurements were acquired during the field survey from survey lines L00 until L57. Data were exported after despiking outlier values (due to high geometric factor, small potential values, or values collected with insufficient current) and removing data with high \% RMS error using a spreadsheet. The resistance values varied from 0.01 to $30 \mathrm{~V} / \mathrm{I}$, as depicted in Figure 9(a). Specifically, the first 12 lines (L00-L12) had much higher group of resistance values (from 0.5 to $30 \mathrm{~V} / \mathrm{I}$ ) and the lines that were over the wreck (L13-L57) mainly have values less than $0.5 \mathrm{~V} / \mathrm{I}$. Regarding the apparent resistivity values (Figure 9(b)), the first lines (L00-L12) have values ranging from 50 to $400 \mathrm{ohm} \cdot \mathrm{m}$, and the rest (L13-L57) have lower values from 1 to $20 \mathrm{ohm} \cdot \mathrm{m}$, reflecting the presence of the wreck in these lines.

After the preprocessing of the raw data, the a priori information was incorporated in each line. Before adding the water column depth in each survey line, the slope was smoothed in both directions $(X, Y)$ : On $X$ direction the vertical distance should be less than the electrode spacing $(a=0.5 \mathrm{~m})$ and on $Y$ direction the vertical distance should be less than the line spacing $(L=1 \mathrm{~m})$. The a priori information was completed after the resistivity value of the river water ( $\left.\rho_{\text {water }}=28 \mathrm{ohm} \cdot \mathrm{m}\right)$ was added at the end of each survey line file.

High initial value of the damping factor (factor $=10$ ) was selected (close to the surface) in order to cope with the high electrical contrast between the high conductive metallic target and the highly resistive background. The inversion for each line was completed using L2-norm (smooth) method for the data and L1-norm (robust) for the model since the target consists of sharp boundaries. Each 2D survey line was filtered individually (according to the \%RMS error) and final 3D model images were produced after inverting all the 58 merged lines.

4.4. Inversion Results. In Figure 10, 12 different depth slices (D1-D12) represent the resistivity distribution at different depths below the river bottom where the first slice $D 1$ is at $\sim 0.10 \mathrm{~m}$ and the last one $D 12$ at $\sim 5.5 \mathrm{~m}$, below the river bottom. The overall resistivity values (displayed on a logarithmic scale) varied from 0.05 to $1500 \mathrm{ohm} \cdot \mathrm{m}$.

At the NNE side of the grid from $x=1 \mathrm{~m}$ to $x=12 \mathrm{~m}$, high resistivity values of $1000 \mathrm{ohm} \cdot \mathrm{m}$ are present in all depth slices (D1-D12) to a maximum depth of $6 \mathrm{~m}$. From $x=12 \mathrm{~m}$ to $x=57 \mathrm{~m}$ the background resistivity value varies from 30 


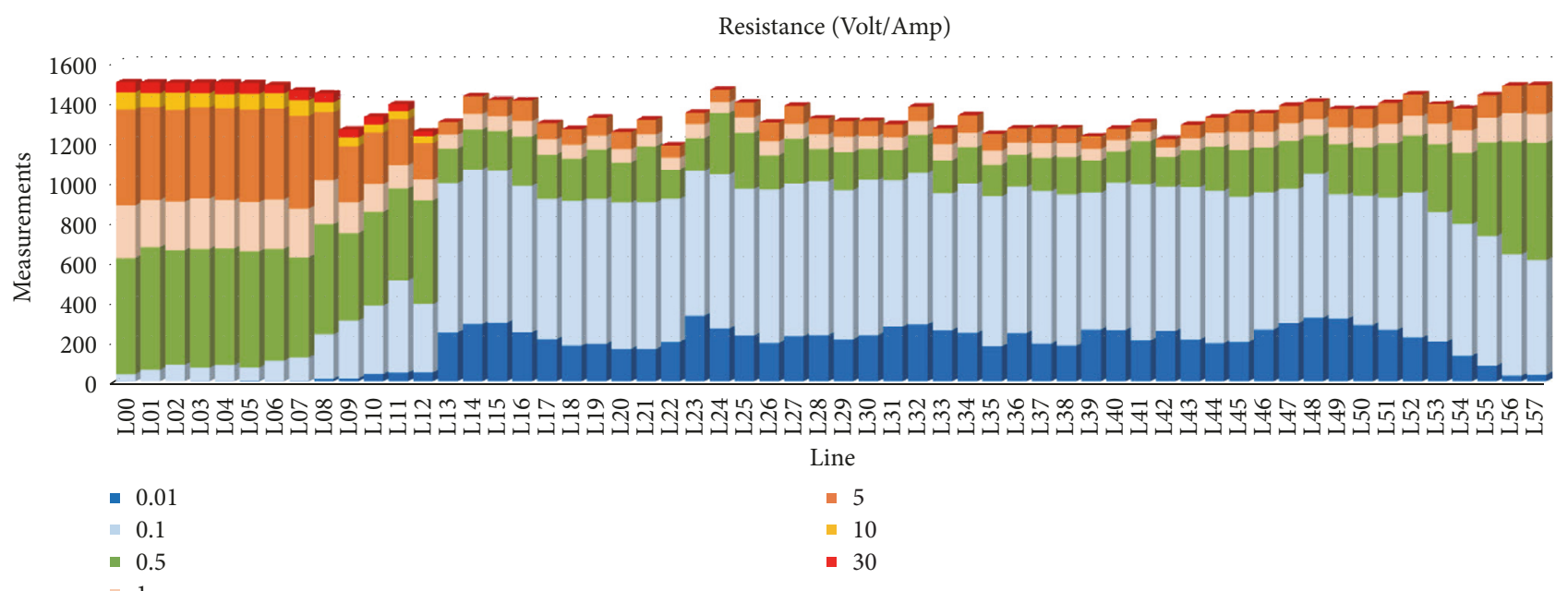

(a)

Ap. Resist. (ohm·m)

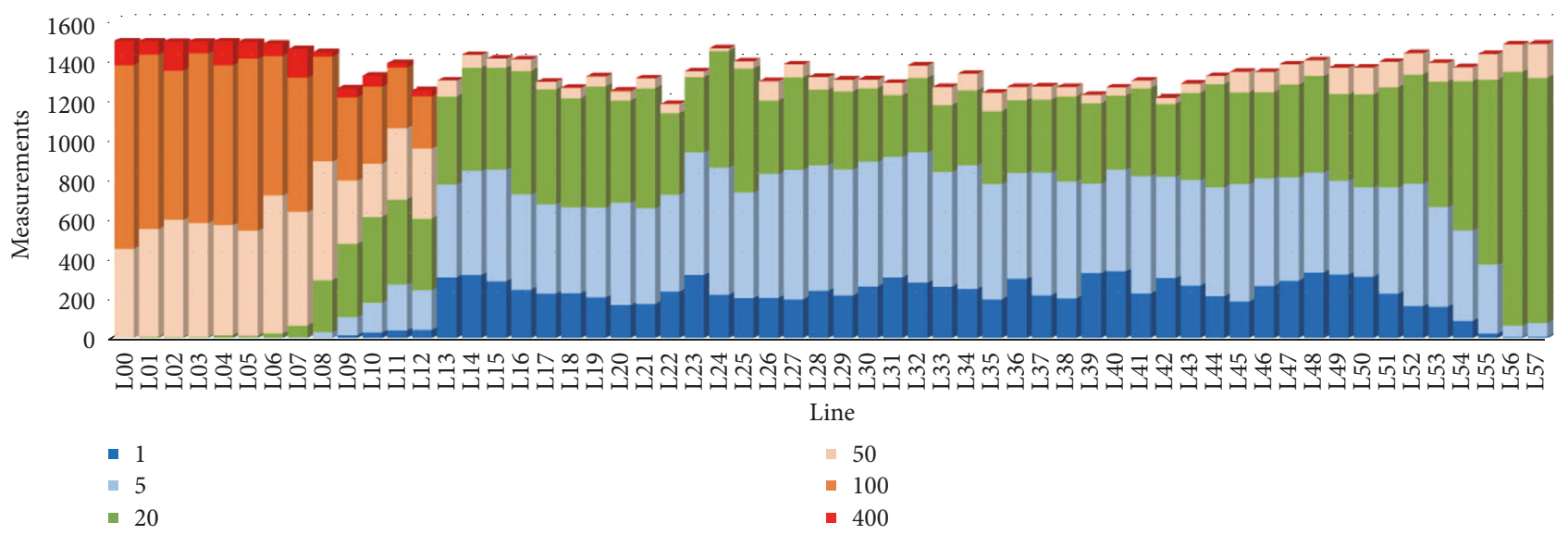

(b)

FIGURE 9: Histograms of resistance (a) and apparent resistivity (b) value per survey line.

to $50 \mathrm{ohm} \cdot \mathrm{m}$, from 0 to $1 \mathrm{~m}$ depth $(D 1-D 4)$, and gradually increases to $1500 \mathrm{ohm} \cdot \mathrm{m}$ into deeper layers till $6 \mathrm{~m}$ depth (D5-D12).

Until the first $0.5 \mathrm{~m}$ of depth $(D 1, D 2)$, the exterior of the hull is difficult to discriminate. After this depth the boundary becomes more resolved to a depth of $1.5 \mathrm{~m}$ (D3-D6) with very low resistivity values that vary from 0.05 to $0.2 \mathrm{ohm} \cdot \mathrm{m}$. These boundaries are confined between $x=11 \mathrm{~m}$ and $x=$ $55 \mathrm{~m}$ and between $y=3 \mathrm{~m}$ and $y=13 \mathrm{~m}$ presenting a structure of $44 \mathrm{~m}$ length and $10 \mathrm{~m}$ width, respectively. From the depth of 1.5 to $4 \mathrm{~m}(D 7-D 10)$ the conductive area becomes wider, presumably showing the ship's deck. After the depth of $4 \mathrm{~m}$ (D11) the conductive area gradually disappears until it completely fades away after $6 \mathrm{~m}$ depth (D12). This is an indication either that the metallic part of the barge is no longer present or that the maximum depth of the barge is $6 \mathrm{~m}$.

Apart from the external boundaries of the ship, internal sections are also resolved in the inversion depth images. At the depth of $\sim 0.6 \mathrm{~m}(D 3)$, a bulkhead (long metallic bar) can be seen running parallel to the centre line of the ship from bow to stern from $x=20 \mathrm{~m}$ to $x=50 \mathrm{~m}$ and at $y=7 \mathrm{~m}$. Furthermore, at $x=22 \mathrm{~m}, 32 \mathrm{~m}$, and $41 \mathrm{~m}$ at a depth of $\sim 1.7 \mathrm{~m}$ (D7) internal sections, perpendicular to the main axis of the ship, are visible as well. A highly resistive anomaly is observed at a depth of 2.5 to $5 \mathrm{~m}$ (D9-D11) located at $x=34 \mathrm{~m}$ to $x=$ $42 \mathrm{~m}$ and at $y=5 \mathrm{~m}$ which is interpreted as a damaged part of the vessel, as validated by the multibeam data (Figure 2).

At the ESE part of the survey grid from $x=11 \mathrm{~m}$ to $x=47 \mathrm{~m}$ and $y=14 \mathrm{~m}$ to $y=16 \mathrm{~m}$ from a depth of 3 to $6 \mathrm{~m}(D 10-D 12)$ a low resistivity area parallel to the main ship axis can be seen with resistivity values close to $0.1 \mathrm{ohm} \cdot \mathrm{m}$. This has been interpreted as a detached part of the ship lying nearby although it may also be an artefact of the inversion process given its location near the boundary of the survey area. The RMS error is estimated as less than 30\%, which may be attributed to the high contrast between the resistivity values of the anomaly related to Crowie and the surrounding substrate.

The inversion model values were exported into commercial 3D graphics software (Voxler). A three-dimensional 

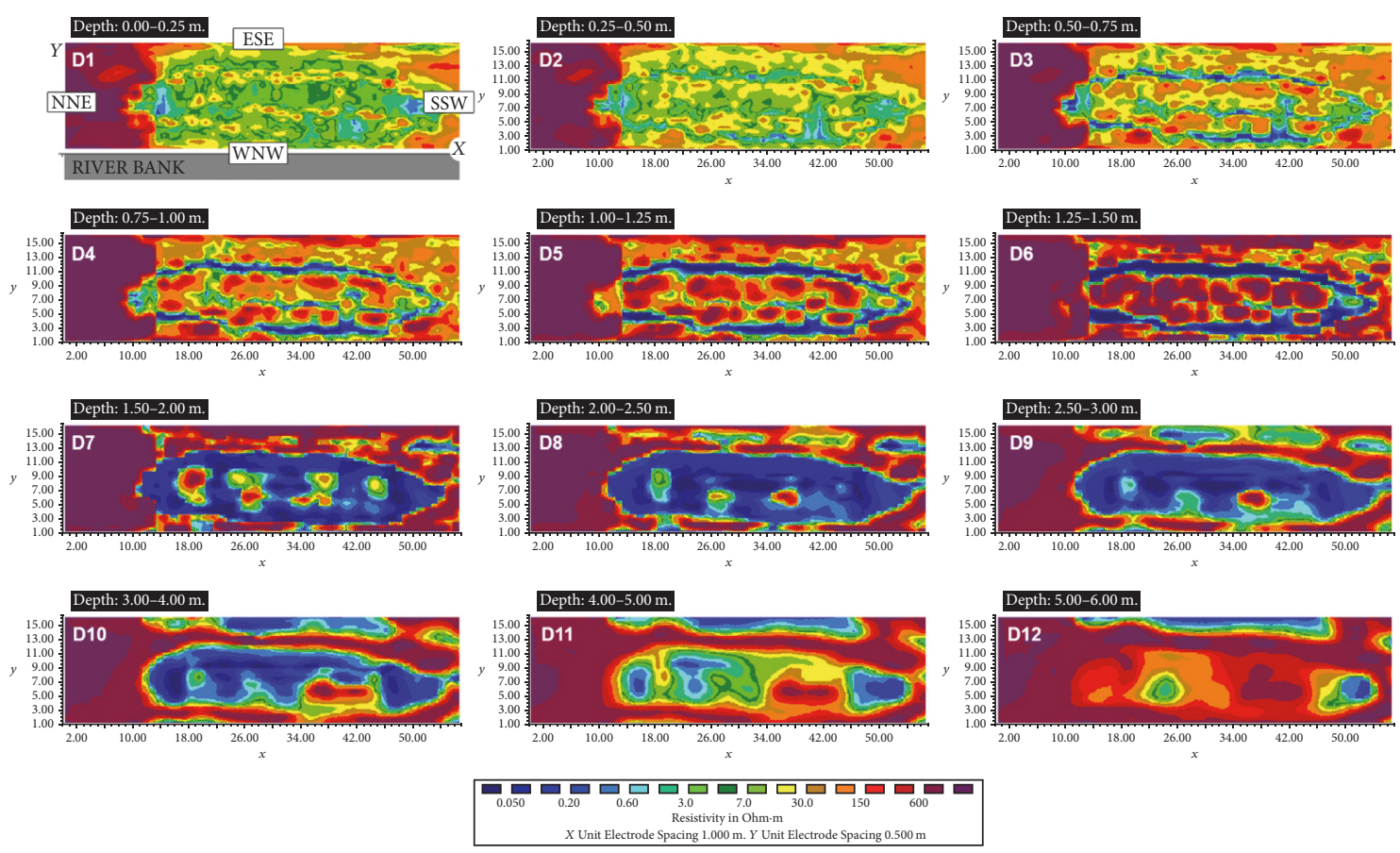

FIGURE 10: 3D inversion depth slices. Resistivity values mapped on a logarithmic scale. Both axes are given in meters.

representation of the barge can be seen in Figure 11, which also includes the bathymetry of the area. The resistivity values are mapped on a logarithmic scale. In Figure 11(a), the water layer (light blue) and the topography (light brown) are shown, using the volume rendered plot mode. In Figure 11(b) selected orthoimages (slices through the model) in all directions $(X$, $Y$, and $Z$ ) are depicted, indicating with dark blue colours the ships' lower resistive areas. The overall volume with the target in it is shown in Figure 11(c) with highly resistive areas denoted by red colour and the target itself is shown in Figure 11(d) depicted with green colour using the isosurface mode of plotting. The isovalue used for ships' metal structure representation is $\rho=0.06 \mathrm{ohm} \cdot \mathrm{m}$. Apart from the outer boundaries of the ship, the internal bulkhead can be seen as well, across the long axis of the ship.

\section{Discussion}

Overall, this study demonstrates that ERT is a suitable technique for investigating shipwrecks in aquatic environments. Despite this potential, some aspects of underwater ERT are more challenging than terrestrial surveys. For example, establishing the survey grid is a time consuming procedure as it is more difficult to set the four corners of the grid at the right position and keep them fixed throughout the survey period. Furthermore, placing the cable on the right position at each different line (if it is floating) is not an easy operation because it depends mainly on the current and wave conditions and any obstacles that might be protruding from the bottom. Any movement of the cable during the data acquisition can increase the noise levels, so extra stabilisation technique is required for some surveys. On the other hand, no metal probes are required since the cable itself is sufficient to propagate the current into the water and the river sediments. After the data acquisition, extra time for the data processing routine is needed since the a priori information including bathymetry and water resistivity should be included for each different survey line. The same arrays and equipment can be used for terrestrial and underwater ERT surveys; however aquatic surveys are more demanding on batteries due to the very conductive environment.

From an archaeological point of view, underwater ERT provides a new means of investigating material culture items that would otherwise be impossible due to turbid water (visual methods) or shallow water depths (acoustic methods).

\section{Conclusion}

The shipwreck Crowie was successfully mapped using ERT deployed underwater in the Murray River. Data from a model simulating the barge structure were obtained and analysed before undertaking the field survey, so that the optimum survey parameters (such as the appropriate array, probe spacing) could be selected according to the particular characteristics of this target and survey area. A priori information, including water column depth and water conductivity, were incorporated throughout the data processing for more accurate model representation.

The field survey involved 58 parallel lines being placed underwater on top of the wreck. Following processing and inversion, the resistivity distribution in the $3 \mathrm{D}$ inversion images clearly shows a conductive target shaped like the structure of a ship. The external boundaries of the ship, due to the low resistivity values (metallic parts), can be 


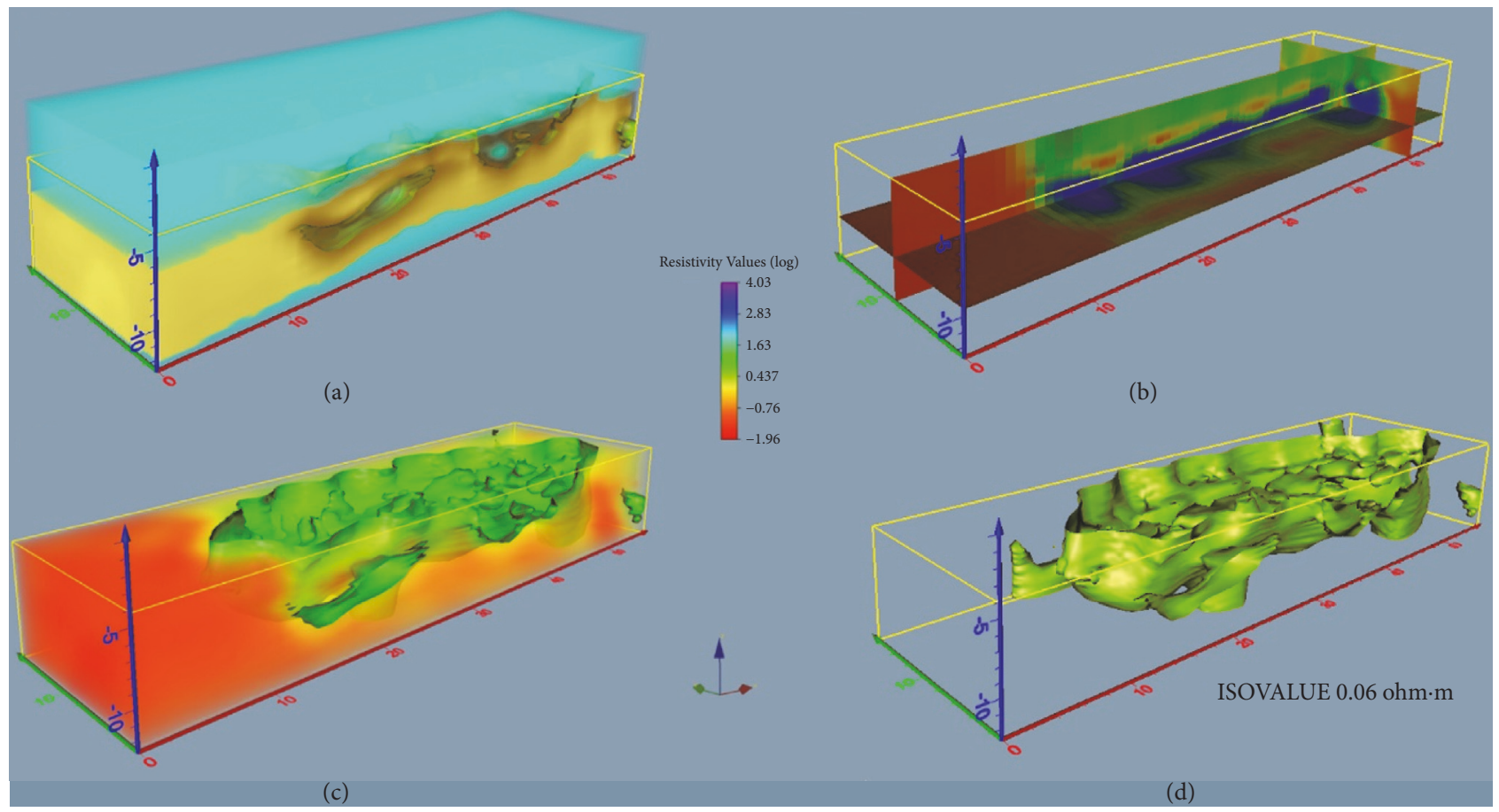

FIGURE 11: 3D model representation of the metallic structure of the Crowie barge. Resistivity values mapped on a logarithmic scale.

distinguished from the highly resistive background (sand and limestone sediments) and they are in good correlation with the historical record. The outer formation of the barge is accurately defined (in accordance with the modelling results) indicating the efficacy of the survey methodology. Apart from the successful imaging of the exterior of the ship, internal compartments of the barge are also visible where they present a suitable resistivity contrast.

Using the ERT method in this novel way to map a submerged barge provides important new information about this geophysical technique and about the wreck of Crowie. This result demonstrates that several important characteristics of a submerged ship can be defined, such as the burial depth of the wreck, the outer limits, overall dimensions, and crucially the shape of the ship. The excellent results obtained from Crowie suggest many future marine archaeological applications of the ERT method.

\section{Conflicts of Interest}

The authors declare that they have no conflicts of interest.

\section{Acknowledgments}

This project was supported by an Endeavour Fellowship to Dr. Kleanthis Simyrdanis funded by the Australian Government. Lee Rippon, John Naumann, Celeste Jordan, Belinda Duke, Shannon Sullivan, and Anika Johnstone contributed to the field work for the project. Thanks are due to Lisa and Barry from the Morgan Waterfront Marina and ZZ Resistivity Imaging for their support of this research. Dr. Ian Moffat is the recipient of Australian Research Council Discovery Early Career Award funded by the Australian Government (DE160100703).

\section{References}

[1] C. Colombero, C. Comina, F. Gianotti, and L. Sambuelli, "Waterborne and on-land electrical surveys to suggest the geological evolution of a glacial lake in NW Italy," Journal of Applied Geophysics, vol. 105, pp. 191-202, 2014.

[2] G. Tassis, P. Tsourlos, J. Rønning, and T. Dahlin, "Detection and Characterization of Fracture Zones in Bedrock: Possibilities and Limitations," in Proceedings of the Near Surface Geoscience 2014 - First Applied Shallow Marine Geophysics Conference, Athens, Greece, September 2014.

[3] D. F. Rucker, G. E. Noonan, and W. J. Greenwood, "Electrical resistivity in support of geological mapping along the Panama Canal," Engineering Geology, vol. 117, no. 1-2, pp. 121-133, 2011.

[4] L. Orlando, "Some considerations on electrical resistivity imaging for characterization of waterbed sediments," Journal of Applied Geophysics, vol. 95, pp. 77-89, 2013.

[5] F. Baumgartner and N. B. Christensen, "Analysis and application of a non-conventional underwater geoelectrical method in Lake Geneva, Switzerland," Geophysical Prospecting, vol. 46, no. 5, pp. 527-541, 1998.

[6] C.-W. Chiang, T.-N. Goto, C.-C. Chen, and S.-K. Hsu, "Efficiency of a marine towed electrical resistivity method," Terrestrial, Atmospheric and Oceanic Sciences, vol. 22, no. 4, pp. 443446, 2011.

[7] C.-W. Chiang, T.-N. Goto, H. Mikada, C.-C. Chen, and S.K. Hsu, "Sensitivity of deep-towed marine electrical resistivity imaging using two-dimensional inversion: A case study on 
methane hydrate," Terrestrial, Atmospheric and Oceanic Sciences, vol. 23, no. 6, pp. 725-732, 2012.

[8] G. Ranieri, F. Loddo, A. Godio et al., "Reconstruction of archaeological features in a mediterranean coastal environment using non-invasive techniques," 2009.

[9] K. Simyrdanis, N. Papadopoulos, J.-H. Kim, P. Tsourlos, and I. Moffat, "Archaeological investigations in the shallow seawater environment with electrical resistivity tomography," Near Surface Geophysics, vol. 13, no. 6, pp. 601-611, 2015.

[10] S. Passaro, F. Budillon, S. Ruggieri et al., "Integrated geophysical investigation applied to the definition of buried and outcropping targets of archaeological relevance in very shallow water," Italian Journal of Quaternary Sciences, vol. 22, no. 1, pp. 33-38, 2009.

[11] S. Passaro, "Marine electrical resistivity tomography for shipwreck detection in very shallow water: A case study from Agropoli (Salerno, southern Italy)," Journal of Archaeological Science, vol. 37, no. 8, pp. 1989-1998, 2010.

[12] R. Parsons, Ships of the inland rivers: An Outline History And Details of All Known Paddle Ships, Barges And Other Vessels Trading on The Murray-Darling System, Gould Genealogy, Modbury, Australia, 3rd edition, 2005.

[13] A. Roberts, W. van Duivenvoorde, M. Morrison et al., "'They call 'im Crowie': an investigation of the Aboriginal significance attributed to a wrecked River Murray barge in South Australia," International Journal of Nautical Archaeology, vol. 46, no. 1, pp. 132-148, 2017.

[14] M. H. Loke and J. W. Lane, "Inversion of data from electrical resistivity imaging surveys in water-covered areas," Exploration Geophysics, vol. 35, no. 4, pp. 266-271, 2004.

[15] C. deGroot-Hedlin and S. Constable, "Occam's inversion to generate smooth, two-dimensional models from magnetotelluric data," Geophysics, vol. 55, no. 12, pp. 1613-1624, 1990.

[16] J. B. Firman et al., Renmark 1:250000 Geological Map, Geological Survey of South Australia, 1971.

[17] P. A. Rogers, "Continental Sediments of the Murray Basin," in The geology of South Australia, J. F. Drexel and W. V. Preiss, Eds., vol. 54, pp. 252-254, The Phanerozoic, South Australia, Australia, 1995.

[18] P. A. Rogers, J. M. Lindsay, N. F. Alley, S. R. Barnett, K. Lablack, and G. LKwitko, "Murray Basin," in The geology of South Australia, J. F. Drexel and W. V. Preiss, Eds., vol. 2, pp. 157-163, The Phanerozoic, South Australia, Australia, 1995.

[19] V. Chaplot, F. Darboux, H. Bourennane, S. Leguédois, N. Silvera, and K. Phachomphon, "Accuracy of interpolation techniques for the derivation of digital elevation models in relation to landform types and data density," Geomorphology, vol. 77, no. 1-2, pp. 126-141, 2006. 

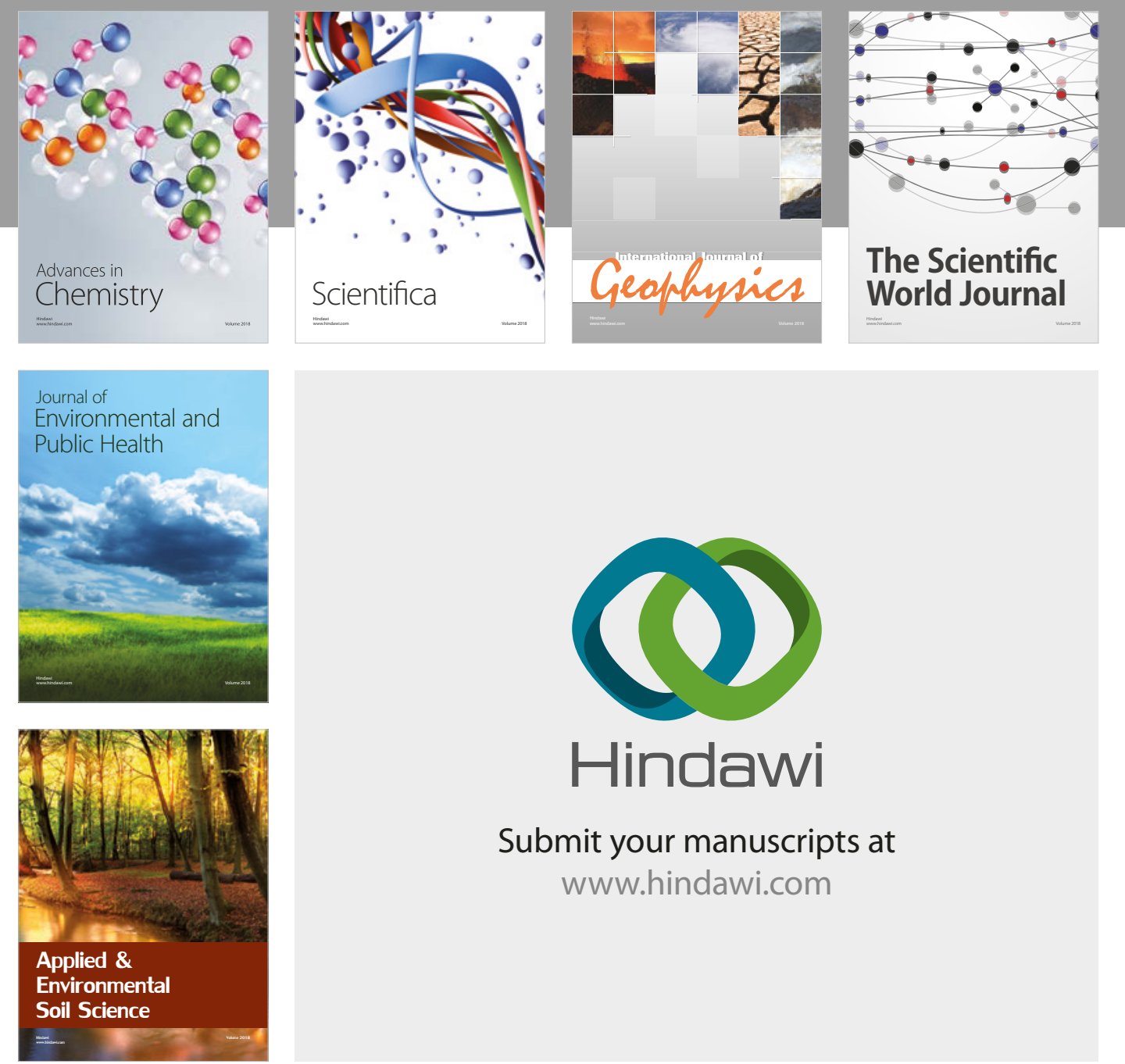

The Scientific

\section{World Journal}
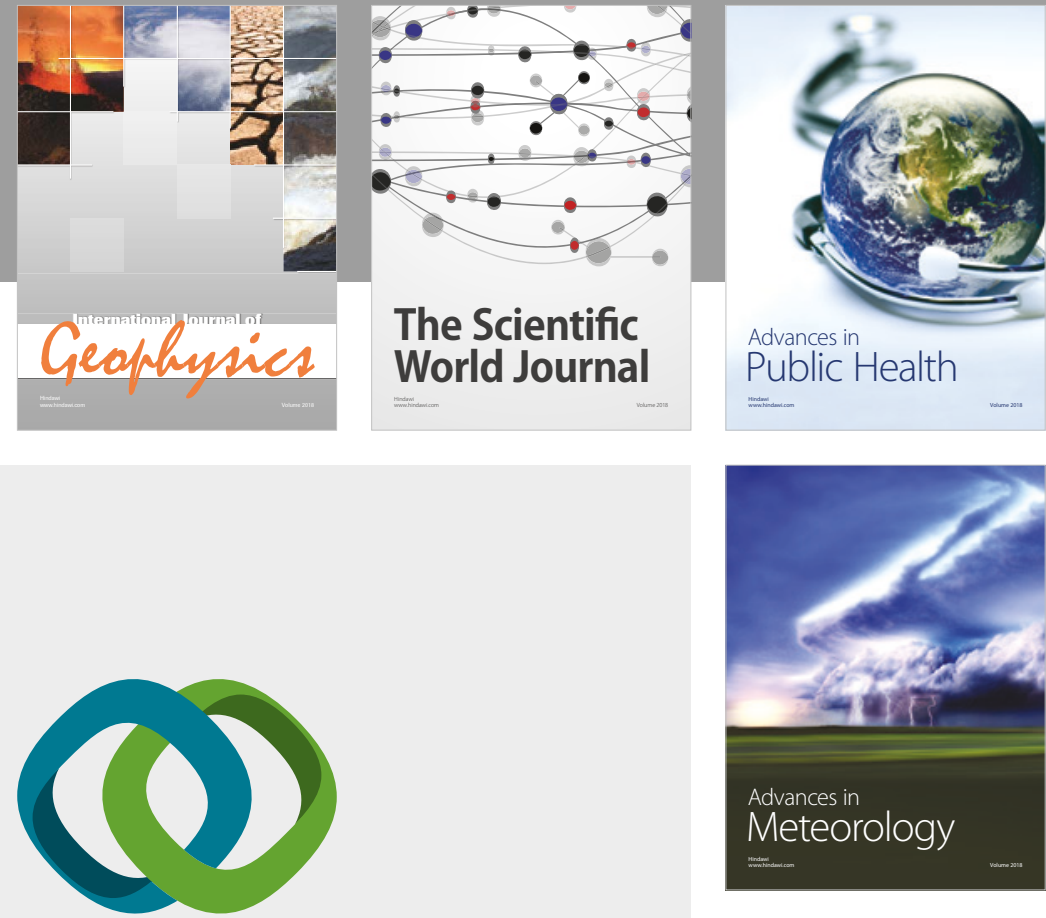

Advan

Public Health

\section{Hindawi}

Submit your manuscripts at

www.hindawi.com
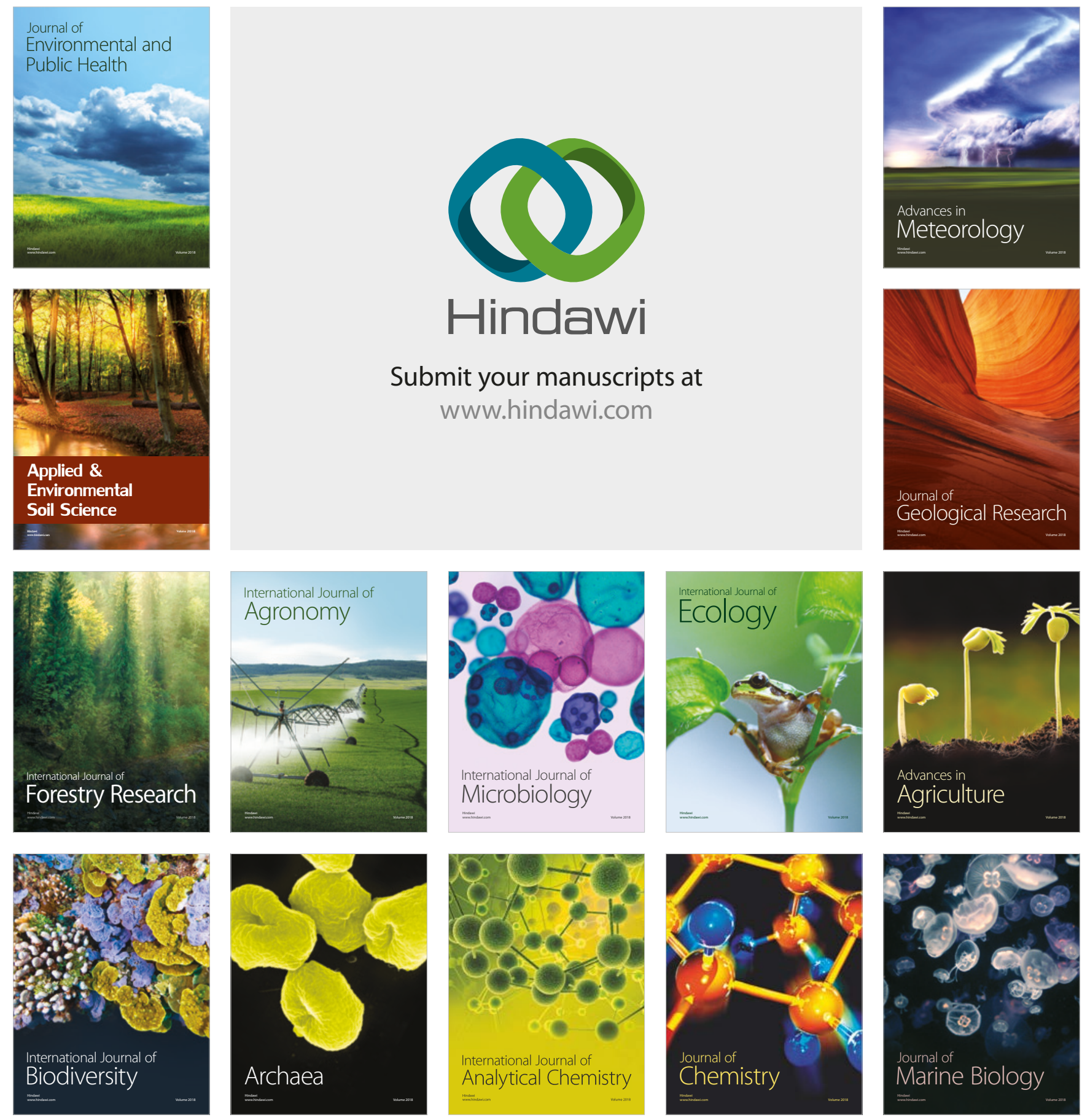